\title{
Burnout, boreout and compassion fatigue on the ICU: it is not about work stress, but about lack of existential significance and professional performance
}

\author{
Erwin J. O. Kompanje*
}

(C) 2018 Springer-Verlag GmbH Germany, part of Springer Nature and ESICM

A 27-year-old ICU nurse mailed me if she could have a private talk with me. 'Outside the hospital and about her work on the ICU,' she wrote.

When I asked him how he is doing, a 59-year-old ICUphysician said he was looking forward for his retirement but that he had to work for another 7 years.

A PICU-manager asked me if I could coach a 39-yearold male nurse. He showed obvious cynicism toward his patients and talked about them as if they were disposable inhumane objects. Several parents had complained about his cynicism.

I met the ICU-nurse in a local coffee shop. Despite her young age, she looked exhausted. She told me that she always wanted to become a nurse, but now she feels detached. She regards herself to be ineffective and complained about lack of accomplishment. She feels overextended. To her horror, she has become a cynic toward the suffering of her patients. Her efficacy in the daily routine work has become reduced. She cried when she told me about the extent of her situation: 'I am incompetent for the job, I have no personal accomplishment anymore but I am still so young, she said. I listened to her and told her I believed she had an existential burnout.

I talked to the ICU-physician when we walked to the hospital parking lot. He told me about boring patients: 'All that comorbidity. It feels like cleaning dust. We fix the symptoms of chronic sick patients who don't have the intention to heal themselves. I put in tubes, drains, try to fix failing organs, but so often in vain. When I became ICU

\footnotetext{
*Correspondence: e.j.o.kompanje@erasmusmc.nl Department of Intensive Care, Erasmus MC University Medical Center, P.O. Box 2040, 3000 CA Rotterdam, The Netherlands
}

physician, it was different. We cured patients, not only stabilized them. It does not satisfy anymore. I told him he shows symptoms of existential boreout. 'How can I be a good doctor if the patients are boring to me?', he asked.

The male PICU-nurse was eager to talk to me. He had become frustrated that he could not save the neonates from debilitating harm like unexpected intracranial hemorrhages. He feels guilty about the parents. This distresses him to such an extent that he became more and more cynical. He told me that he always had given those patients and their parents extra attention, talking with them as much as he could. 'But now I detached myself from the parents. I do not care if they grieve for their child. To my horror I disengage, he said. I told him that I think he suffers from compassion fatigue.

It is often said that working in an ICU can be especially stressful because of the severity of illness of the patients and the subsequent high mortality, giving rise to regular traumatic and ethical issues and challenging daily work. If it is so stressful to work on an ICU, why then will most of the ICU-nurses and ICU-physicians never develop burnout, boreout or compassion fatigue? The roots of burnout, boreout and compassion fatigue lie in people's need to believe that their lives are meaningful, that the things they do are important, make sense and give existential significance. When people feel to have failed, being insignificant and making no difference, they start to feel helpless, hopeless and they crash. I do not believe that work stress is the most important factor in these conditions, but that it is correlated with the sense of accomplishment and having influence and meaningful recognition. 
I told the three ICU healthcare providers that their work is still important and that they, being dedicated nurses and a doctor, can make a significant contribution. I focused on the values of professional performance as the intrinsic and professional drive for excellence; working from the perspective of humanity towards patients, but also towards colleagues and other healthcare professionals and the willingness for critical self-reflection.

In additional meetings, we focused on their existential perspective with a focus on active engagement in deliberate practice in order to improve particular tasks and skills. The experienced healthcare providers were told that the superior performance does not develop from extensive experience, academic education and domainrelated knowledge. This leads to automatism in many skills and tasks (that is where they were now). Motivated experts continues to improve their performance as a function of more experience.

Colleagues with signs of burnout and boreout should be giving insight that their performance is automated. They must be offered a task with a well-defined goal; should be motivated to improve; be provided with feedback and ample opportunities for repetition and gradual refinements of their performance. This shall lead to deliberate practice for a given individual. They should be helped by well-performing colleagues, coaches and educators. Usually the help is successful. The focus for 'cure' should not be on reducing stress. Stressful events on the ICU will not go away. It is inherent to working on the ICU, and is not the cause of the three conditions. What will help these healthcare workers are providing an existential perspective on working as an expert in modern medicine and an ICU.

\section{Compliance with ethical standards}

\section{Conflicts of interest}

This manuscript has not been published elsewhere and is not submitted simultaneously for publication elsewhere. There are no relevant conflicts of interest.

Received: 14 January 2018 Accepted: 30 January 2018

Published online: 21 February 2018 